The presence of analytical dependencies describing the process of static soil puncture by a working body with a conical asymmetric tip is necessary to create installations with the ability to control the trajectory of the soil puncture.

The paper considers the features of the process of interaction of an asymmetric conical tip with the ground. Analytical relationships were obtained to determine its reactions during a static puncture, the deviation of the head trajectory from a straight line, to determine the size of the soil compaction zone and the magnitude of the destructive force that acts on adjacent communications and other underground objects. It was found that with an increase in the value of the displacement of the top of the cone, for example, from its axis from $0.02 \mathrm{~m}$ to $0.08 \mathrm{~m}$ with a borehole diameter of $0.2 \mathrm{~m}$, the value of soil resistance increases almost four times. The greatest resistance is achieved when piercing a hard sandy sand.

It was found that with an increase in the displacement of the tip of the tip cone, the deviation of the trajectory increases. The piercing head achieves the greatest deviation from the straight trajectory of movement with a sharper cone and a greater asymmetric deviation of its top, and, for example, in hard sandy loam can be up to $0.17 \mathrm{~m}$ with a span of $10 \mathrm{~m}$.

It was found that the size of the soil destruction zone will be almost 1.8 times larger than the tip in the form of a symmetrical cone and reaches from 8 to 12 borehole diameters, depending on the type of soil. The maximum pressure on adjacent objects can reach from $0.06 \mathrm{MPa}$ in hard-plastic clay to 0.09 MPa in hard sandy loam.

The calculated dependences obtained for determining the power and technological parameters depending on the geometric dimensions of the asymmetric tip of the working body can be used to create installations with a controlled static puncture for use in the most common soil conditions

Keywords: trenchless technologies, ground puncture, utilities, working body, traffic control
UDC 624.132 .3

DOI: $10.15587 / 1729-4061.2021 .230256$

\title{
DETERMINATION OF THE REGULARITIES OF THE SOIL PUNCHING PROCESS BY THE WORKING BODY WITH THE ASYMETRIC TIP
}

Svyatoslav Kravets

Doctor of Technical Sciences, Professor Department of Building, Road, Melioration, Agricultural Machinery and Equipment

National University of Water and Environmental Engineering Soborna str., 11, Rivne, Ukraine, 33028

E-mail: s.v.kravets@nuwm.edu.ua

VIadimir Suponyev Doctor of Technical Sciences, Associate Professor*

E-mail: v-suponev@ukr.net

Sergi Bales ny i Director

Design Institute of Transport Infrastructure LTD Otakara Yarosha str., 18, Kharkiv, Ukraine, 61045

E-mail: tbalesna@gmail.com

Valery Shevchenko

$\mathrm{PhD}$, Associate Professor* E-mail: valery03102016@gmail.com A l exander Y e f y m e $\mathrm{k}$ o $\mathrm{PhD}$, Associate Professor*

E-mail:khadi.alef@gmail.com

Vitaliy Ragulin

$\mathrm{PhD}$, Associate Professor*

E-mail: ragulinrvn@ukr.net

*Department of Construction and Road-Building Machinery Kharkiv National Automobile and Highway University Yaroslava Mudrogo str., 25, Kharkiv, Ukraine, 61002

Received date 18.02.2021 Accepted date 19.04.2021 Published date 20.04.2021
How to Cite: Kravets, S., Suponyev, V., Balesnyi, S., Shevchenko, V., Yefymenko, A., Ragulin, V. (2021). Determination of the
regularities of the soil punching process by the working body with the asymetric tip. Eastern-European Journal of Enterprise Technologies, 2 (1 (110)), 44-51. doi: https://doi.org/10.15587/1729-4061.2021.230256

\section{Introduction}

Trenchless laying of engineering communications is actively spreading in all countries of the world. Among the existing methods for the formation of wells for the implementation of this technology, the method of static ground penetration is popular. The main disadvantage of the traditional puncture method is the lack of accuracy of movement when piercing the head in the array. To achieve the aim, it is necessary to constantly adjust the trajectory of movement. Motion control is possible through the use of a general-purpose head with an asymmetric accumulator and the impact on it of postulate-postulate-rotational motion from the power plant. This process requires a lot of effort and energy consumption.

The trenchless laying of engineering communications is actively distributed in all countries of the world. Among the existing methods for the formation of wells for the implementation of this technology, the method of static ground penetration is popular. The main disadvantage of the traditional puncture method is the lack of accuracy of movement when piercing the head in the array. To achieve the goal, it is necessary to constantly adjust the trajectory of movement. Motion control is possible through the use of a general-purpose head with an asymmetric accumulator and the impact on it of 
postulate-rotational motion from the power plant. This process requires a lot of effort and energy consumption. Therefore, an urgent task is to improve the methods for calculating the resistance of the soil to a puncture and to ensure the control of the trajectory of movement of the soil-pubching head with an asymmetric cone. This is carried out by determining the magnitude of its deviation depending on the type of soil and its physical and mechanical authorities.

\section{Literature review and problem statement}

The development of urban infrastructure constantly requires the construction of new engineering networks, imposes certain restrictions on builders [1]. The laying of underground communications from the digging of trenches causes significant social problems and economic costs that arise in connection with the stoppage of traffic, complications of freight and passenger traffic. Therefore, the trenchless method of laying underground utilities is becoming more and more widely used, including when laying large-diameter pipelines, which can be performed in combination with microtuning methods [2]. The improvement of construction technologies goes in different directions. One of the ways is aimed at increasing the efficiency of the control system of the trajectory of movement of the working body in the soil by increasing the accuracy of determining it in the soil and creating devices for indicating obstacles in the path of movement in the form of cables and pipelines [3]. Effective laying of underground utilities by the trenchless method is ensured by correctly selected technologies for creating horizontal wells, which is considered in [4]. The main disadvantage of these technologies is their cost, which comes from the high cost of drilling equipment and the cost of work. Of the various methods available on the market for obtaining technological voids in soil, static soil puncture is simple and cheap [5]. But this comparison can only be valid for short track sections within 25-30 m among the methods that form straight wells. The laying of pipelines over long distances by the formation of a controlled leader puncture is considered by the authors in [6]. But the nature of the tip and the influence of yogic parameters on the process are not considered.

The general laws governing the processes of ground penetration and the formation of horizontal wells are described in [7]. The process of interaction of the soil-piercing working body with the soil was considered in work [8]. But the studies carried out by the author of this work are aimed only at increasing the efficiency of the process of penetration into the soil of a working body with a symmetrical conical tip, but do not give answers about increasing the accuracy of penetration or changing the trajectory of the working body in the soil. For the same reason, the research results in [9] have a narrow distribution of results only within short distances. The process of interaction of an asymmetric tip with the ground during a controlled puncture is not considered in [10]. The destructive effect of radial soil compaction during the creation of a well by a static method on adjacent communications, road foundations and foundations of structures is considered in [11]. However, calculations of the size of the soil compaction zone around the well are not given. The need to take into account soil compaction when laying a route near underground structures and utilities is also considered in [12]. But the determination of the forces acting on nearby communications from the elastic state of the soil during its compaction with an asymmetric tip is irreducible. It is possible to reduce the destruction zone by using the pipe pushing method. Then, according to [13], soil compaction outward will not occur. However, the recommendations obtained in the work apply only to working bodies with ring-shaped tips. Investigations to determine the force of penetration of the soil with a conical tip are given in [14]. The dependence of the frontal resistance of the soil on its geometric parameters is given [15]. It should be determined that the calculated dependences obtained in $[14,15]$ are of an empirical nature and cannot be used for the case of a soil puncture by a working body with an asymmetric tip. In contrast to [16], in [17] the establishment of soil reactions and the magnitude of deviation from the axial movement of the working body with such a tip were solved analytically, taking into account the known standard soil properties. The influence of the pipe material on its pasture, which determines the rational well trajectory, is considered in [18]. But studies on the impact on the process of puncturing the soil with a conical asymmetric tip are not given.

Analytical models for calculating the technological and design parameters of equipment with an asymmetric tapered tip were not found in the literature search.

\section{The aim and objectives of research}

The aim of research is to establish the regularities of the process of ground penetration by a working body with an asymmetric tip and, on their basis, to develop technological and constructive theoretical calculated dependencies for installations for trenchless laying of underground communications.

To achieve this aim, it is necessary to solve the following objectives:

- to determine the force of soil resistance to displacement and lateral deflecting force, which act on the asymmetric conical tip;

- to determine the amount of deflection of the head with an asymmetric cone as it moves in the soil mass;

- to establish the size of the destruction zone around the asymmetric conical tip and determine the force of soil pressure on the adjacent underground communications.

\section{Materials and methods for investigating the process of soil puncture by a soil-piercing working body with an asymmetric conical tip}

The theoretical research methods carried out are based on the theories of soil mechanics and their cutting, soil puncture and traditional methods of analyzing research results. Confirmation of the reliability of the results of the obtained individual provisions of the theory of the process occurred by comparing them with practical and experimental data.

\section{The results of the study of the process of puncturing the soil with a working body with an asymmetric conical tip}

5. 1. Determination of the force of soil resistance to displacement and lateral deflecting force that act on an asymmetric tapered tip

The calculated scheme of the action of the soil resistance forces on the asymmetric conical tip of the soil-piercing working body is shown in Fig. 1. 


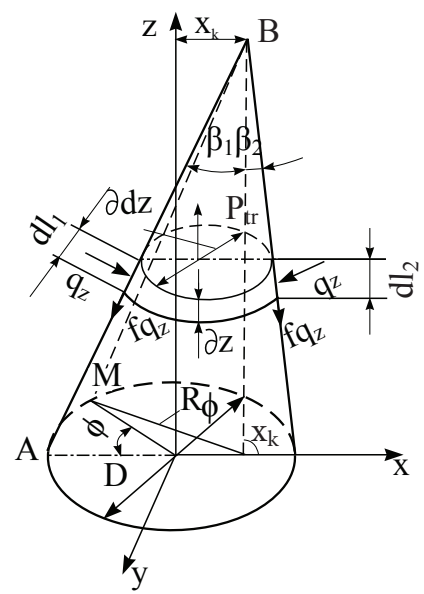

Fig. 1. Design scheme for determining the action of soil resistance forces on a tip with an asymmetric cone

To calculate the force of the axial force of resistance of the soil to the puncture and its dependence on the value of the displacement of the apex of the cone, which let's represent as the distance $x_{k}$ from its projection onto the $x$-axis at point $C$ (Fig. 1).

According to the previously obtained method [17], it is first necessary to determine the regularity of the change in soil density along the height of the cone on the basis of the law of equality of the soil masses before and after its puncture. To do this, it is necessary to determine the areas of the lateral surface of the asymmetric cone from the condition of limiting its sharpening, at which the east of the soil from the walls of the cone should be provided. To do this, through its geometric dimensions, consider the tangents of the angles of deflection of the apex of the cone and $\operatorname{tg} \beta_{2}$, which have the form:

$$
\operatorname{tg} \beta_{1}=\frac{R+x_{k}}{H} ; \operatorname{tg} \beta_{2}=\frac{R-x_{k}}{H},
$$

where $R$ - radius of the base of the cone; $H$ - height of the cone; $x_{k}$ - value of the displacement of the apex of the cone along the $x$ axis.

To prevent the formation of a soil core of compaction at the apex of the cone, when the soil is guaranteed to come off the forming surface, its sharpening should be at least $2 \beta_{1} \leq 50^{\circ}$ [5], that is:

$$
\operatorname{tg} \beta_{1}=\frac{R+x_{k}}{H} \leq 0.466,
$$

So,

$$
\frac{E_{k}}{H} \leq 0.466-\frac{R}{H} ; \quad \frac{E_{k}}{H} \leq 0.466-\frac{R}{H},
$$

The lateral (half) area of an elementary truncated cone is:

$$
\begin{aligned}
& \Delta S_{b_{1}}=\frac{\pi \cdot d l_{1}}{2}\left(\frac{d_{z}}{2}+\frac{d_{z}}{2}+\partial d_{z}\right) ; \\
& \Delta S_{b_{2}}=\frac{\pi \cdot d l_{2}}{2}\left(\frac{d_{z}}{2}+\frac{d_{z}}{2}+\partial d_{z}\right),
\end{aligned}
$$

where $\partial d_{z}$ - elementary increase in the diameter of the truncated cone at the height $\partial z$.

$$
\begin{aligned}
& d l_{1}=\frac{\partial z}{\cos \beta_{1}} ; d l_{2}=\frac{\partial z}{\cos \beta_{2}} ; d_{z}=\frac{D}{H}(H-Z) ; \\
& \cos \beta_{1}=\frac{1}{\sqrt{1+\operatorname{tg}^{2} \beta_{1}}}=\frac{1}{\sqrt{1+\left(\frac{R+x_{k}}{H}\right)^{2}}} ; \\
& \sin \beta_{1}=\frac{\frac{R+x_{k}}{H}}{\sqrt{1+\left(\frac{R+x_{k}}{H}\right)^{2}}} ; \\
& \cos \beta_{2}=\frac{1}{\sqrt{1+\operatorname{tg}^{2} \beta_{2}}}=\frac{1}{\sqrt{1+\left(\frac{R-x_{k}}{H}\right)^{2}}} \\
& \sin \beta_{2}=\frac{\frac{R-x_{k}}{H}}{\sqrt{1+\left(\frac{R-x_{k}}{H}\right)^{2}}} .
\end{aligned}
$$

Thus, the selected area will be equal to:

$$
\begin{aligned}
& \Delta S_{b_{1}}=\frac{\pi}{2} \cdot \frac{D}{H}(H-z) \sqrt{1+\left(\frac{R+x_{k}}{H}\right)^{2}} \cdot \partial z ; \\
& \Delta S_{b_{2}}=\frac{\pi}{2} \cdot \frac{D}{H}(H-z) \sqrt{1+\left(\frac{R-x_{k}}{H}\right)^{2}} \cdot \partial z .
\end{aligned}
$$

Let's determine the law of change of soil density by the height of the cone on the basis of the law of equality of soil masses before and after the puncture:

$$
\frac{\pi D^{2}}{4} \rho_{p}=\frac{\pi}{4}\left(D^{2}-d_{z}^{2}\right) \rho_{z}=\frac{\pi}{4}\left[D^{2}-\frac{D^{2}}{H^{2}}(H-z)^{2}\right] \rho_{z} .
$$

So,

$$
\rho_{z}=\frac{\rho_{p}}{1-\left(\frac{H-z}{H}\right)^{2}} .
$$

Then the normal soil pressure in each cross section of the cone will be equal to:

$$
\begin{aligned}
& q_{z}=\frac{(1+\omega) \rho_{s}}{C_{c}}\left(\frac{1}{\rho_{n}}-\frac{1}{\rho_{z}}\right)= \\
& =\frac{(1+\omega) \cdot \rho_{s}}{C_{c} \rho_{n}}\left[1-1+\left(\frac{H-z}{H}\right)^{2}\right]=E_{s} \cdot\left(\frac{H-z}{H}\right)^{2},
\end{aligned}
$$

where $E_{s}=\frac{(1+\omega) \cdot \rho_{s}}{C_{c} \rho_{n}}-$ compression modulus of soil deformation; $\omega$ - natural soil moisture; $C_{c}$ - soil compression coefficient; $\rho_{s}$ - density of the solid phase of the soil (the density of the soil, provided that there are no pores in it); $\rho_{z}$ - variable soil density along the height of the cone is proportional to the change in the cross-sectional area of the cone; $\rho_{n}$ - density of the soil in its natural state.

To determine the frontal resistance to punching $P_{p}$, let's represent it in differential form:

$$
\begin{aligned}
& \partial P_{p}=q_{z} \Delta S_{b_{1}} \sin \beta+f q_{z} \Delta S_{b_{1}} \cos \beta_{1}+ \\
& +q_{z} \Delta S_{b_{2}} \sin \beta_{2}+f q_{z} \Delta S_{b_{2}} \cos \beta_{2}= \\
& =q_{z} \cdot \Delta S_{b_{1}}\left(\sin \beta_{1}+f \cos \beta_{1}\right)+q_{z} \cdot \Delta S_{b_{2}}\left(\sin \beta_{2}+f \cos \beta_{2}\right) .
\end{aligned}
$$


Taking into account expressions (3)-(6) after intermediate transformations let's obtain:

$$
\partial P_{p}=\pi E_{s} \frac{D}{H^{3}}\left(f+\frac{D}{2 H}\right)(H-z)^{3} \partial z .
$$

then, after integrating expression (11), let's obtain:

$$
\begin{aligned}
& P_{p}=\pi E_{s} \frac{D}{H^{3}}\left(f+\frac{D}{2 H}\right) \int_{0}(H-z)^{3} \partial z= \\
& =\frac{\pi E_{s} D H}{4}\left(f+\frac{D}{2 H}\right) .
\end{aligned}
$$

The transverse (deflecting) force $P_{x}$ was determined in a similar way. Its differential expression is:

$$
\begin{aligned}
& \partial P_{x}=q_{z} \cdot \Delta S_{b_{1}}\left(\cos \beta_{1}-f \sin \beta_{1}\right)- \\
& -q_{z} \cdot \Delta S_{b_{2}}\left(\cos \beta_{2}-f \sin \beta_{2}\right)=-\pi f E_{s} \cdot \frac{D}{H^{4}} x_{k}(H-z)^{3} \partial z .
\end{aligned}
$$

Integrating (13) let's obtain:

$$
\begin{aligned}
& P_{x}=-\pi f E_{s} \cdot \frac{D}{H^{4}} x_{k} \int_{0}(H-z)^{3} \partial z= \\
& =\left.\frac{\pi f E_{s}}{4} \cdot \frac{D}{H^{4}} x_{k}(H-z)^{4}\right|_{0}=\frac{\pi f E_{s} D x_{k}}{4} .
\end{aligned}
$$

If $E_{k}=D / 2$, then this deflecting force would be:

$$
P_{x}=f E_{s} \cdot \frac{\pi D^{2}}{8} \text {. }
$$

The dependences of the forces of frontal resistance of the soil (12) on the magnitude of the sharpening of the asymmetric cone in the form of the ratio of its radius of the base, equal to half the diameter of the piercing head to the height for different soils are shown in Fig. 2.

The dependences of the lateral (deflecting) force $P_{x}$ of the frontal resistance of the soil (14) on the value of the displacement of the apex of the asymmetric cone for different soils and diameters of piercing heads are shown in Fig. 3.

The graphs shown in Fig. 2, 3 were obtained for the most common types of grants, in which a communication cavity can be formed by piercing them with a static method. The calculations included the following initial data [17]: soil deformation moduli: sandy loam $E_{s}=1.36 \mathrm{MPa}$, loam $E_{s}=0.892 \mathrm{MPa}$; clay $E_{s}=0.63 \mathrm{MPa}$. Friction forces of soils against steel are also laid down: for sandy loam $f=0.532$, for $\operatorname{loam} f=0.424$, for clay $f=0.325$.

As can be seen from the graphs in Fig. 2, with an increase in the sharpening of the cone within $50^{\circ}$, the resistance to soil puncture decreases by $2.2-2.5$ times. And from Fig. 3 it can be seen that when the deflection of the cone is $x_{k}$ from $0.02 \mathrm{~m}$ to $0.08 \mathrm{~m}$, for example, with a borehole diameter of $0.2 \mathrm{~m}$, the value of the deflecting force increases almost threefold.
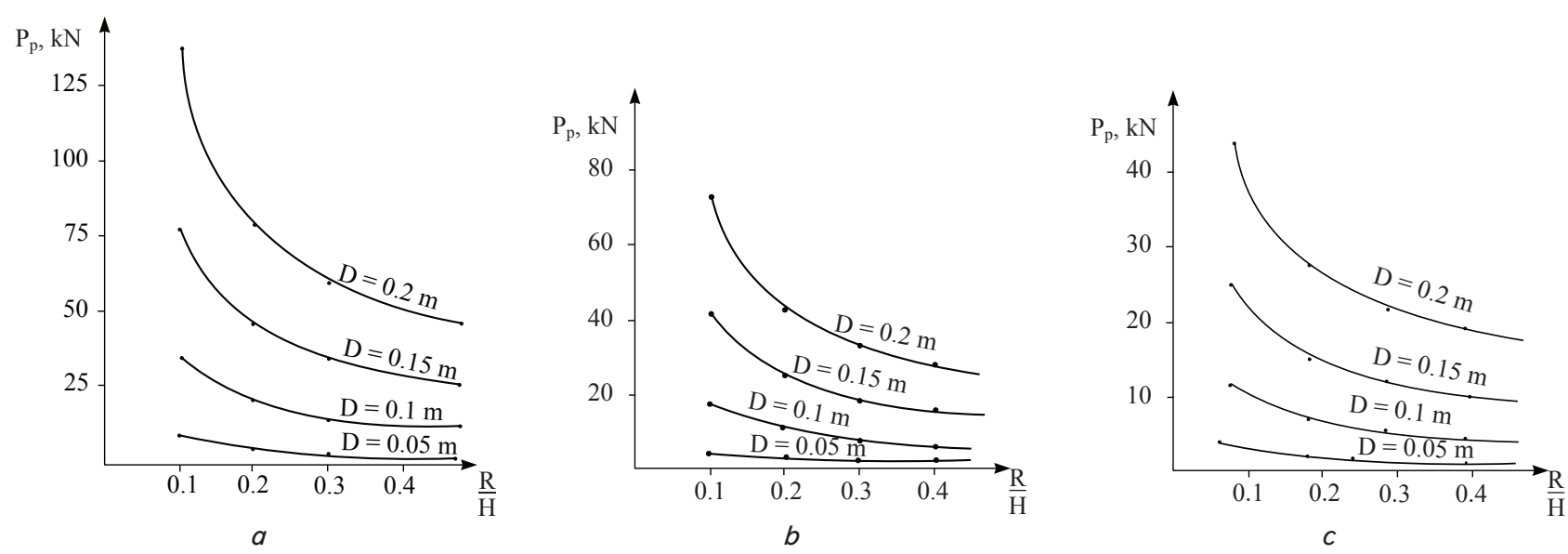

Fig. 2. Dependences of the frontal resistance of the soil on the sharpening of the asymmetric cone for different diameters of piercing heads and different soils: $a-$ in solid sandy loam; $b$ - in semi-hard loam; $c$ - in tight plastic clay
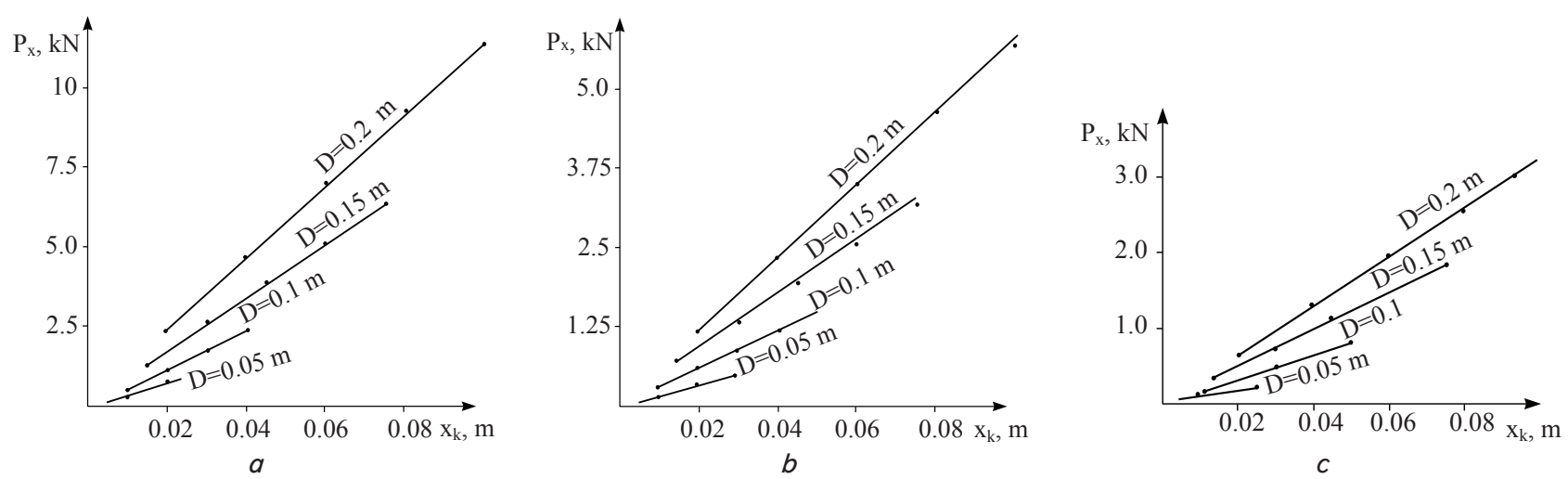

Fig. 3. Dependences of the transverse (deflecting) force $P_{x}$ of the frontal resistance of the soil on the value of the displacement of the apex of the asymmetric cone at a distance $x_{k}$ and diameters of piercing heads for soils: $a-$ in solid sandy loam; $b-$ in semi-hard loam; $c-$ in hard-plastic clay 
It is also seen that the greatest resistance and deflecting force will be when piercing solid sandy loam. This is 3.6 times more than in hard-plastic clay and 2 times more than in semihard loam.

The results obtained can be waste wood when choosing the technical characteristics of power plants in accordance with the technological tasks and the soil environment in which engineering communications must be laid.

5. 2. Determination of the deflection value of the head with an asymmetric cone during its advance in the soil mass

In the process of rotation of the conical asymmetric tip around its axis and the action of an axial force on it, the tip moves along a rectilinear path. After the termination of the rotational movement, the tip, under the action of the soil reaction, is deflected towards the fixed direction of displacement of the cone. As it was established in [17], its maximum deviation depends on the design parameters of the tip and pushing the rods, their mechanical properties and physical and mechanical properties of the soil, is pierced. For this, the drive rod end is regarded as a beam on a resilient base on which the reaction of the soil acts. The equation for determining the deflection (deflection) for such a problem has the form [19]:

$$
\Delta_{p}=\frac{P_{x}}{8 E_{b} I \beta_{n}^{3}}
$$

where $E_{b}$ - modulus of elasticity of the rod during bending $\left(E_{b}=2 \cdot 10^{7} \mathrm{~N} / \mathrm{cm}^{2}\right) ; I$ - the moment of inertia of the crosssection of the tip; $\beta_{n}$ - coefficient depending on the ratio of the stiffness of the rod and the elastic foundation (soil), [19]:

$$
\beta_{p}=b \sqrt[4]{\frac{k_{p}}{4 E I}},
$$

where $k_{b}$ - the bed (base) coefficient (for soils of medium density, $k_{b}=5-50 \mathrm{~N} / \mathrm{cm}^{2}$ ), [20].

For an annular section of the working body and taking into account dependencies (14) and (16), equation (15) after re-adjustment will take the form:

$$
\Delta_{p}=1.96 \frac{E_{s}}{E_{b}} \cdot \frac{f x_{k}}{D^{2} \frac{\gamma^{4}-1}{\gamma^{4}} \beta_{p}^{3}},
$$

where $\gamma=D / d$ - the ratio, respectively, of the outer diameter of the tip to the inner diameter.

According to dependence (14), the deflecting force will reach its maximum value if the cone is deepened to its entire height. In this case, the tip will deviate from the trajectory of rectilinear motion by a distance $\Delta_{r},(17)$. To evade the tip from the rectilinear motion path for a certain distance, it needs to travel a length without torque transmission (without rotation). Their ratio depending on the displacement of the cone can be written as:

$$
\frac{L}{S}=\frac{0.51 H D^{3} E_{b}\left(\gamma^{4}-1\right) \beta_{b}^{3}}{f E_{s} x_{k} \gamma^{4}},
$$

where $L$ - length of movement; $S$ - lateral deviation.

The boundaries of the condition of the east of the soil from the generatrix of the surface of the cone can be written as:

$$
H=\frac{D}{2 \lambda},
$$

where $\lambda=0.1 \ldots 0.5$, or $R / H=0.1 \ldots 0.5$.
The results of calculating the ratio $L / S$ depending on the displacement of the apex of the asymmetric cone $x_{k}$.and its height in the form of a ratio $R / H$ for common soil types are shown graphically in Fig. 4 . In the calculations, the bed coefficient $\beta_{b}$ was taken from the condition: $k_{b}=0.3 \mathrm{MPa}$, the modulus of elasticity of the steel $\operatorname{rod} E_{b}=2 \cdot 10^{5} \mathrm{MPa}$; the moment of inertia of the cross section $I=0.04 \cdot D^{4} \mathrm{~m}^{4}$.

$$
\beta_{n}=\sqrt[4]{\frac{0.3 \mathrm{MPa}}{4 \cdot 2 \cdot 10^{5} \cdot 0.04 D^{4}}}=\frac{0.055}{D} \mathrm{~m}-1 .
$$

The following initial data were also included in the calculations. Modules of soil deformation [20]: sandstone $E_{s}=1.36 \mathrm{MPa}$, loam $-E_{s}=0.892 \mathrm{MPa}$; clays $-E_{s}=0.63 \mathrm{MPa}$. Values of diameters: $D=0.05 ; 0.10 ; 0.15 ; 0.2 \mathrm{~m}$, and the ratio $=1.5$.
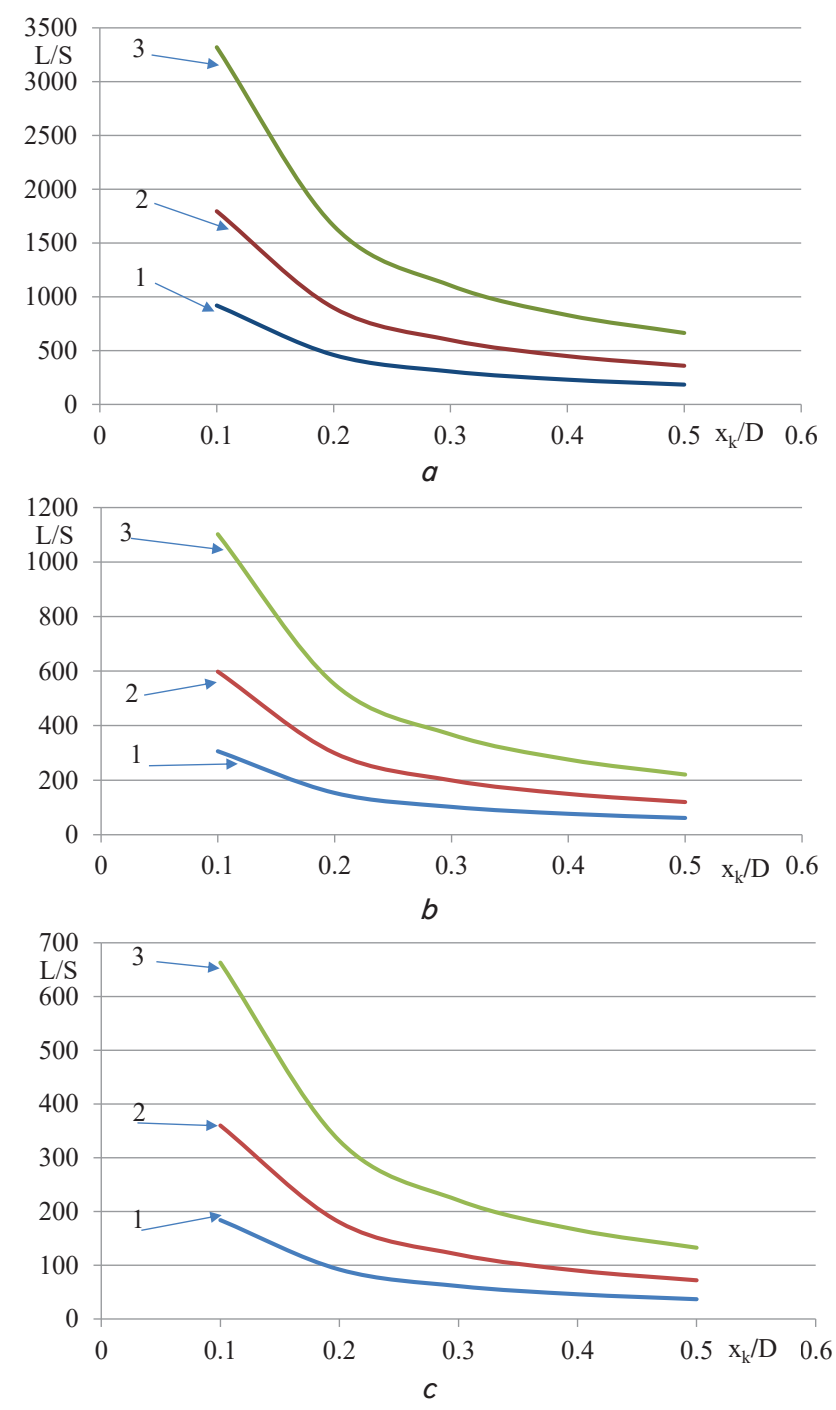

Fig. 4. Calculations of the ratio $L / S$ for common soil types depending on the displacement of the top of the asymmetric cone $x_{k}$ for the cases: $a-R / H=0.1 ; b-R / H=0.3$; $c-R / H=0.5 ; 1-$ hard sandy loam; 2 - semi-hard loam; 3 - refractory clay

From the obtained graph (Fig. 4) it can be seen that with an increase in the displacement value of the tip of the tip cone, the deviation of the trajectory increases. The greatest deviation from the straight trajectory of movement when piercing 
the head is achieved with a greater deviation of the apex of the asymmetric tip compared to the symmetrical one, that is, with a smaller value of the displacement $x_{k}$. It is also possible to see that the smaller the angle of sharpening of the tip cone, the less will be the deflection of the working member.

Thus, depending on the physical and mechanical properties of the soil and the elasticity of the push rod, it is possible to determine the rational value of the deflection of the tip of the asymmetric cone of the tip by piercing the head.

\section{3. Establishment of the zone of destruction and de-} termination of the force of soil pressure on the adjacent underground communications

The conical tip, in which the vertex is offset by $x_{k}$ relative to the center of the base, has a variable length of the cone, which depends on the variable radius of rotation $R_{\varphi}$ (Fig. 1).

The radius $R_{\varphi}$ is determined from $\triangle O M K$ based on the cosine theorem:

$$
R_{\varphi}=\sqrt{R^{2}+x_{k}^{2}+2 x_{k} R \cos \varphi} .
$$

This radius changes with the height of the cone:

$$
\begin{aligned}
& R_{\varphi}=\frac{H-z}{H} \sqrt{R^{2}+x_{k}^{2}+2 x_{k} R \cos \varphi} R_{\varphi}= \\
& =\sqrt{R^{2}+x_{k}^{2}+2 x_{k} R \cos \varphi},
\end{aligned}
$$

where $R=D / 2$ - radius of the base of the cone; $H$ - height of the cone.

Lets determine the size of the soil destruction zone by an asymmetric cone on the basis of the law of equality of soil masses before and after a puncture:

$$
\frac{\pi D_{p}^{2}}{4} \rho_{p}=\frac{\pi}{4}\left(D_{p}^{2}-4 R_{\varphi}^{2}\right) \rho_{s}
$$

where $\rho_{n}$ - natural soil density to destruction; $\rho_{a v}$ - average soil density in the destruction zone after puncture [6]:

$$
\rho_{s}=\frac{\lambda^{2} \rho_{p}}{\lambda^{2}-1}
$$

where $\lambda=4.0 \ldots 6.0$ is a coefficient that depends on the type of soil and the depth of the puncture [6].

From equation (2), taking into account (3), after intermediate transformations, let's determine the size of the soil destruction zone:

$$
D_{p}=2 \lambda R_{\varphi}=2 \lambda \frac{H-z}{H} \sqrt{R^{2}+x_{k}^{2}+2 x_{k} R \cos \varphi} .
$$

That is, the destruction zone depends on the angle of rotation $\varphi$, which means that the density of the soil in each longitudinal section depends on its angle of rotation and the distance from the base of the cone.

The maximum value of the destruction zone will be at $z=0$. In this case, if $x_{k}=0 ; D_{p}=2 \lambda R . x_{k}=R$ and $\varphi=0$; $D_{p}^{\max }=4 \lambda R=2 \lambda D$.

Thus, if the top of the cone is displaced by the value $x_{k}=R$, then its destruction zone is 2 times larger than the destruction zone of a symmetric cone with the same base radius.

Determine the soil pressure of the asymmetric cone on underground utilities.
In the first approximation, the regularity of the change in density $\rho_{x}$ can be assumed to be linear depending on the distance from the side wall of the hole along the fracture zone to the value of $D_{p}[5]$ (Fig. 5):

$$
\rho_{x}=\rho_{m}+\left(1-\frac{x}{D_{p}-\frac{D}{2}}\right)\left(\rho_{\max }-\rho_{p}\right),
$$

where $\rho_{\max }-$ maximum soil density in the sidewall of the well.

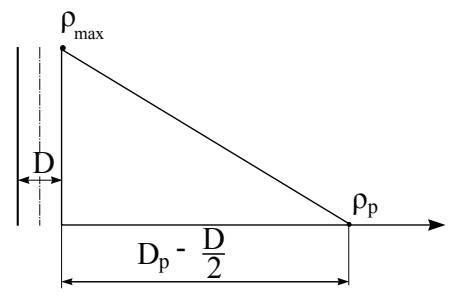

Fig. 5. The accepted pattern of changes in soil density along the destruction zone

The dependence, reflecting the regularity of the pressure change at a distance from the asymmetric conical tip, after transformations takes the form:

$$
\begin{aligned}
& q=\frac{(1+\omega) \rho_{s}}{C_{k} \rho_{n}}\left(1-\frac{\rho_{n}}{\rho_{x}}\right)= \\
& =E_{s}\left[\begin{array}{c}
\left.1-\frac{\rho_{n}}{\rho_{n}+\left(1-\frac{x}{D_{p}-\frac{D}{2}}\right)\left(\rho_{\max }-\rho_{p}\right)}\right]
\end{array} .\right.
\end{aligned}
$$

Considering that:

$$
\rho_{a v}=\frac{\rho_{\max }+\rho_{n}}{2}=\frac{\lambda^{2} \rho_{n}}{\lambda^{2}-1} .
$$

Then the pressure of compacted soil on underground utilities is equal to:

$$
q=E_{g}\left[1-\frac{1}{1+\left(1-\frac{x}{D_{p}-\frac{D}{2}}\right) \frac{2}{\lambda^{2}-1}}\right] \cdot \sqrt{b^{2}-4 a c} .
$$

The maximum pressure on underground communications will act if $x=0$ :

$$
q_{\max }=\frac{2 E_{s}}{\lambda^{2}+1} \text {. }
$$

For hard sandy loam $-q_{\max }=(0.054 \ldots 0.066) E_{s}$.

For semi-hard loam $-q_{\max }=(0.083 \ldots 0.103) E_{s}$.

For hard-plastic clay $-q_{\max }=(0.103 \ldots 0.118) E_{s}$.

If the average soil density in the destruction zone is, according to experimental data for sandy-clayey soils, 
$\rho_{a v}=(1.05 \ldots 1.1) \rho_{n}[5]$, then the maximum pressure on underground utilities is $q_{\max }=(0.09 \ldots 0.17) E_{s}$.

\section{Discussion of the results of the study of the process of controlled soil puncture with an asymmetric conical tip}

The obtained understanding of the processes of soil puncture made it possible to establish the calculated dependences for determining the components of the soil resistance forces from the advance of the tip in the massif - the frontal resistance (12) and the lateral force (14). As the calculations of the frontal resistance of the soil puncture have shown (Fig. 2), the process involves the application of significant forces on the equipment. The greatest resistance occurs when piercing a semi-hard sandy loam, which is 3.6 times more than in a refractory clay and in fact 2 times more than in a semi-hard loam. It was also found that with an increase in the sharpening of the cone within $50^{\circ}$, the resistance to puncture of the soil decreases by $2.2-2.5$ times.

The obtained analytical dependence (14) for determining the deflecting force made it possible to determine (Fig. 3) that when the deflection of the cone is from $0.02 \mathrm{~m}$ to $0.08 \mathrm{~m}$ with a borehole diameter of $0.2 \mathrm{~m}$, the value of the deflecting force increases by almost three times.

When determining the deviation of the working body with an asymmetric conical tip (18), the rigidity of the working body structure and the properties of the soil medium in the form of the bed coefficient were taken into account. From the above graph (Fig. 4) it is shown that the deviation value may differ by more than 4 times depending on the displacement of the top of the cone and the types of soil that is pierced.

The definition of the soil compaction zone around the asymmetric tip and the destructive effect from the stress state of the soil on the adjacent communications or other underground structures was established using the law of conservation of soil masses before and after compaction. The calculated dependence for determining the compaction zone for various parameters of the asymmetric cone and soil conditions is described by formula (23), and the pressure of stressed soil on nearby communications is determined by formula (27). An understanding of their significance is important for the practical use of static soil puncture when laying engineering communications along a complex trajectory.

All the dependences obtained take into account the parameters of the asymmetric conical tip and the normative data on the physical and mechanical properties of soils and are analytical in nature. This is the main difference from other studies that have been devoted to the process of ground penetration and are of an empirical nature, which limits their scope of use $[5,8,15,16]$. The proposed analytical dependences make it possible to conduct a comprehensive qualitative analysis of the influence of the main factors that determine the features of the soil puncture by an asymmetric cone.

The practice of using installations for static soil perforation and theoretical and experimental studies of other authors [5, 8, 15, 16, 21-23] testify to the correspondence of the calculated values obtained to the real data.

The results obtained regarding existing machines and installations for trenchless laying make it possible to improve their technological processes and working equipment. The re- commendations are limited to the conditions of development of thawed soils, its most common types. They do not relate to the conditions for laying communications in frozen soils, in soils of increased hardness, high humidity and in sands. Their development requires additional means of intensifying work processes, which require appropriate further research.

\section{Conclusions}

1. The provided theoretical substantiation and the regularities of the soil puncture process were established, at the basis of creating dependencies for determining the components of the soil resistance force to the advancement of the asymmetric conical tip of the working body. The obtained analytical dependencies made it possible to determine the influence of the determining factors on the process, such as the design parameters of the working equipment and the physical and mechanical properties of the soil environment. It was found that with an increase in the sharpening of the cone within $50^{\circ}$, the resistance to soil puncture decreases by $2.2-2.5$ times. When the deflection of the cone is from $0.02 \mathrm{~m}$ to $0.08 \mathrm{~m}$ with a borehole diameter of $0.2 \mathrm{~m}$, the value of the deflecting force increases almost threefold. The greatest resistance and deflecting force will be when piercing hard sandy loam, which is 3.6 times more than in refractory clay and in fact 2 times more than in semi-hard loam.

2. The obtained calculated dependence for determining the deflecting force made it possible to determine the amount of deflection of the head with an asymmetric conical tip. At the same time, the design features of the soil-piercing head and the pushing rod were taken into account, the properties of the material from which they are made and the physical and mechanical properties of soils are pierced. It was found that effective control of the head movement in the soil is possible if the angle at the tip of the tip cone is less than $50^{\circ}$. This is a condition for creating a core of the seal, which in its shape approaches a symmetrical cone, on which forces in space are balanced, and which cannot affect the deflection process of the tip.

3. A theoretical substantiation of the process of creating a soil destruction zone around the asymmetric tip is given and its dimensions are determined. It was found that on the opposite side of the displacement of the cone, this zone is almost 2 times larger in comparison with the usual tip in the form of a symmetrical cone. The dependence for determining the regularity of the change in soil pressure at a distance from the side wall of the hole along the destruction zone is based on a linear equation. On this basis, the values of the maximum soil pressure on adjacent communications were obtained, which is determined by the volumetric deformation of each type of soil, which reaches $0.06 \mathrm{MPa}$ in hard-plastic clay and $0.09 \mathrm{MPa}$ in solid sandy loam.

\section{Acknowledgement}

The team of authors expresses sincere gratitude to the staff of the Kharkiv National Automobile and Highway University and the Rivne National University of Water Management and Environmental Management, who, together with the authors, take part in scientific research to improve machines and installations for trenchless laying of underground communications. 


\section{References}

1. Zwierzchowska, A., Kuliczkowska, E. (2019). The selection of the optimum trenchless pipe laying technology with the use of fuzzy logic. Tunnelling and Underground Space Technology, 84, 487-494. doi: http://doi.org/10.1016/j.tust.2018.11.030

2. Adams, E. (2007). Latest developments for the trenchless construction of pipelines. Oil Gas-European Magazine, 33, (2), $62-66$.

3. Zhao, J., Ling, B. (2014). Trenchless technology underground pipes. Shanghai: Machinery Industry Press, 134.

4. Cohen, A., Ariaratnam, S. (2017). Developing a Successful Specification for Horizontal Directional Drilling Pipelines. Planning and Design 2017. Phoenix: 45. doi: http://doi.org/10.1061/9780784480878.050

5. Eshutkin, D. N., Smirnov, Yu. M., Tsoy, V. M., Isaev, V. L. (1990). Vysokoproizvoditelnye gidropnevmaticheskie udarnye mashiny dlya prokladki inzhenernykh kommunikatsiy. Moscow: Stroyizdat, 176.

6. Kravets, S. V., Kovanko, V. V., Lukianchuk, O. P. (2015). Naukovi osnovy stvorennia zemleryino-yarusnykh mashyn i pidzemnorukhomykh prystroiv. Rivne: NUVHP, 322.

7. Kruse, G. (2009). The trenchless technique horizontal directional drilling. Soil related risk and risk mitigation. 4th Pipeline Technology Conference, 134-156.

8. Romakin, N. E., Malkova, N. V. (2007). Parametry rabochego instrumenta dlya staticheskogo prokola gruta. Stroitelnye i dorozhnye mashiny, 11, 31-33.

9. Kravets, S., Suponyev, V., Rieznikov, O., Kosiak, O., Nechydiuk, A., Klets, D., Chevychelova, O. (2018). Determination of the resistance of the cylindricaltubular drill for trenchless laying of underground communications. Eastern-European Journal of Enterprise Technologies, 3 (7 (93)), 64-70. doi: http://doi.org/10.15587/1729-4061.2018.131838

10. Tsung, N., Zheng, M., Najafi, M., Mehraban, S. (2016). A Comparative Study of Soil Pressure and Deformation of Pipes Installed by the Open-Cut Method and Trenchless Technology. Pipelines 2016 Out of Sight, Out of Mind, Not Out of Risk. Shanghai, 135. doi: http://doi.org/10.1061/9780784479957.132

11. Asperger, M., Jeremic, B. (2012). Examination of the Cavity Expension Model: Predicting Hydrofracture During Horizontal Directional Drilling. ECI 284: Theoretical Geomechanics. Term Project, 256-267.

12. Raksha, S., Anofriev, P., Kuropiatnyk, O. (2019). Simulation modelling of the rolling stock axle test-bench. E3S Web of Conferences, 123, 01032. doi: http://doi.org/10.1051/e3sconf/201912301032

13. Perepechko, Y., Kireev, S., Sorokin, K., Imomnazarov, S. (2019). Use of Parallel Technologies for Numerical Simulations of Unsteady Soil Dynamics in Trenchless Borehole Drilling. Parallel Computational Technologies, 1063, 197-210. doi: http://doi.org/ 10.1007/978-3-030-28163-2_14

14. Posmituha, O., Kravets, S., Suponyev, V., Glavatsky, K. (2018). Determination of equivalent and optimal sizes of wedge tip from flange for the static perforation of soil. MATEC Web of Conferences, 230, 01011. doi:10.1051/matecconf/201823001011

15. Zemskov, V. M., Sudakov, A. V. (2005). Analiz issledovaniya lobovogo soprotivleniya pri bestransheynoy prokladke truboprovodov metodom prokola. Izvestiya TulGU. Seriya Podemno-transportnye mashiny i oborudovanie, 6, 35-38.

16. Gusev, I. V., Chubarov, F. L. (2014). Primenenie upravlyaemogo prokola grunta pri bestransheynoy prokladke trub. Potentsial sovremennoy nauki, 2, 30-33.

17. Lunys, O., Neduzha, L., Tatarinova, V. (2019). Stability research of the main-line locomotive movement. Proc. of the 23rd Int. Sci. Conf. Transport Means 2019 pt III. Palanga: Kaunas Univ. of Technology, 1341-1345.

18. Cherkashin, S. (2016). Installation of the Pipelines Made of Ductile Iron (DI) With the Usage Of Horizontal-directional Drilling Technique (HDD) For Water Supply Treatment Service and Sewerage Pipelines Construction and Reconstruction. Procedia Engineering, 165, 717-725. doi: http://doi.org/10.1016/j.proeng.2016.11.769

19. Belyaev, N. M. (1962). Soprotivlenie materialov. Moscow: Fizmatgiz, 608.

20. Goldshteyn, M. N. (1979). Mekhanicheskie svoystva gruntov (napryazhenno-deformirovannye i prochnostnye kharakteristiki gruntov). Moscow: Stroyizdat, 304.

21. Khachaturian, S. L. (2013). Fizychne modeliuvannia ta bahatofaktornyi eksperyment dlia vyznachennia zusyllia prokoliuvannia robochym orhanom aktyvnoi diyi. Zbirnyk naukovykh prats (haluzeve mashynobuduvannia, budivnytstvo), 1 (36), $238-243$.

22. Rogachev, A. A. (2006). Formirovante upravlencheskogo resheniya pri opredelenii rezhimov gornykh vyrabotok na osnovanii matematicheskogo iodelirovaniya. Izvestiya TulGU. Seriya «Ekonomika. Upravlenie. Finansy», 3, 356-360.

23. Romakin, N. E., Malkova, N. V. (2006). Usilie vnedreniya i optimalniy ugol zaostreniya rabochego nakonechnika pri staticheskom prokole rrunta. Stroitelnye i dorozhnye mashiny, 10, 35-39. 